\title{
Mental health and multicultural societies in the Europe of the nineties*
}

\author{
Patricia D'Ardenne, District Psychologist, Enfield Health Authority; \\ and Suman Fernando, Consultant Psychiatrist, Mental Health Unit, \\ Chase Farm Hospital, Enfield, Middlesex EN2 8JL
}

This conference was attended by nearly 200 participants from 15 countries, $50 \%$ being from the European Community, mostly professionals with a known interest in improving mental health services for ethnic minorities. The first plenary session, with two keynote speakers, emphasised the importance of considering the special problems of refugees and asylum seekers from non-European countries living in Europe and highlighted the problems presented by racism and professional ethnocentricism. Subsequent sessions addressed questions of inequality, aspects of integration and socialisation, difficulties in diagnosis and treatment and finally the problem of providing appropriate and acceptable services for black people in Europe. The workshops and seminars focused on diverse topics ranging from transcultural theoretical questions to practical issues of service provision.

Although impressive in terms of the number of speakers, time for discussion was very limited and social issues effecting ethnic minorities in Europe were hardly touched on. Deficiencies within the current approaches to mental health care for black people were mentioned but the implications of this for the organisation of services were not pursued very far. In fact it was not until the very last day that speakers came round to addressing the possible need for separate services for black people perhaps staffed by black people. The British contributions were extensive and radical, covering both cultural and racial issues. Drs Suman Fernando and A. Majid

* An international conference, sponsored by the World Health Organization and Stichting Overlegorgaan Geestelijke Gezondheidszorg (SOGG) held at Rotterdam from 15 to 18 September 1991. gave keynote addresses, the former emphasising the need for new approaches in psychiatry and the latter for the formation of a transcultural institute based in Europe. One symposium dealt with social conditions and mental health of four British ethnic communities, namely, the African/West Indian, Cypriot, Indian, and Irish. In other symposia, Ms R. Atma described the work of the Asian Family Counselling Service, Ms Anna Greenwood reviewed the conflicts that face mental health professions from ethnic communities, and Mrs Patricia d'Ardenne presented a multicultural perspective on sexual and marital therapy, drawing on work with the Bangladeshi population in East London.

Although there are similarities across Europe in the overall mental health issues that relate to ethnic minorities, such as the racism encountered by black people resident in Europe and the problems arising from linguistic and cultural barriers between providers and users of services, there are marked differences in specifics within the issues and, more significantly, differences in approach to problems. Also, there are problems of communication-evident, for example, in the confusion that arose by the use of the term 'migrants' by many non-British European colleagues to describe people that British participants preferred to call ethnic communities or black people. This conference afforded a unique opportunity for the sharing of ideas and observation; it should lead to closer co-operation in examining the way mental health should be conceptualised and mental health care practised in a multicultural Europe where racism and political pressures are creating tremendous difficulties for people who are seen as 'alien' to the traditional cultures of Europe. 